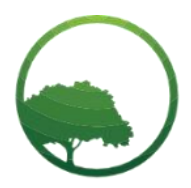

Research in Business \& Social Science

IJRBS VOL 10 NO 8 ISSN: 2147-4478

\title{
Technology orientation and innovation capability in the digital transformation process of SMEs: A review
}

\author{
(D) Achmad Mamduh ${ }^{(a) *(10)}$ Heri Pratikto ${ }^{(b)}$ \\ (a) Doctoral Program in Management Science, Malang State University, Jalan Semarang, No: 5, 65145, Malang, East Java, Indonesia \\ (b) Professor, Faculty of Economics and Business, Malang State University, Jalan Semarang, No: 5, 65145, Malang, East Java, Indonesia
}

\begin{tabular}{l} 
A R T I C L E I N F O \\
\hline Article history: \\
Received 03 December 2021 \\
Received in rev. form 20 Dec. 2021 \\
Accepted 27 December 2021 \\
Keywords: \\
Technology Orientation, Innovation \\
Ability, Digital Transformation, \\
MSME \\
JEL Classification: \\
M29
\end{tabular}

\begin{abstract}
A B S T R A C T
From various reviews about innovation, this article will discuss technology orientation and innovation capabilities through digital transformation 4.0 in small businesses. There is a need to examine the relationship between the two from a useful perspective about see toward using various studies related to technology orientation and innovation capabilities in the industrial era 4.0. This study aims to increase understanding of technology orientation and innovation capabilities in the context of small businesses through Digital Transformation 4.0 by reviewing the empirical literature. The articles presented can guide further studies related to technology orientation with innovation capabilities so that it can be easily understood by researchers and entrepreneurs among small businesses.
\end{abstract}

(C) 2021 by the authors. Licensee SSBFNET, Istanbul, Turkey. This article is an open access article distributed under the terms and conditions of the Creative Commons Attribution (CC BY) license (http://creativecommons.org/licenses/by/4.0/).

\section{Introduction}

Small and medium enterprises (MSMEs) are business activities run by individuals, households, or small business entities. Small and medium enterprises are important parts of the economy in providing employment in the private sector. In this study, a deductive review was conducted to determine the effect of technology orientation and innovation capability on the digital transformation process of MSMEs.

It is necessary to develop innovation capabilities that can process their resources into useful new products, services, methods or systems (Al-Kaouti et al., 2020). The presence of innovation capabilities is very important for developing innovation because it gives companies the flexibility to improve their products according to changing market expectations in maintaining growth (Liu et al., 2018). Therefore, companies can improve their company performance through the transformation of their resources into valuable results and competitive advantage (Martínez-Román, Tamaro \& Gamero, 2017).

Product innovations are also very important and needed by MSMEs, the development of more modern products will strengthen competitiveness and business sustainability (Hilmersson \& Hilmersson, 2020) an important determinant of superior company performance (Siahaan \& Tan, 2020). In the process, it involves Entrepreneurial Psychology, Packaging and Labeling, as well as several innovations in product manufacturing, even in MSME financial literacy that requires technology orientation and innovation capabilities from business actors.

\footnotetext{
* Corresponding author. ORCID ID: 0000-0001-7453-7255

(C) 2021by the authors. Hosting by SSBFNET. Peer review under responsibility of Center for Strategic Studies in Business and Finance.

https://doi.org/10.20525/ijrbs.v10i8.1529
} 
In addition to the entrepreneurial orientation, which can affect the financial performance of MSMEs is the technology orientation. Information technology refers to all forms of technology used in creating, storing, changing, and using information in all its forms. Technology is a physical component in the form of products, equipment, blue prints, techniques and processes, and information is a method in management, marketing, production, quality control, functions and competencies. Technology orientation sharpens business positions and applications, including managing data analysis to improve business situations that occur, sharpening business strategies for MSMEs by using software in marketing systems (e-commerce). Technology orientation plays an important role in improving MSME financial performance. Innovation is common in industrial scale companies, developing innovations in companies to ensure their success in the market. This article will review the technology orientation and innovation capability. The definition of innovation capability as "Innovation capability is defined as the company's ability to transform its knowledge, capabilities, and assets into new products, services, methods, organizational systems, and management that can provide benefits to interested parties" (Hogan et al., 2011). The need to start the innovation process early can foster an innovative and open-minded organizational culture that is constantly developing new ideas and products. A faster pace of innovation will enable companies to meet the challenges that arise in a rapidly changing environment, will be able to change the market environment more proactively (Hilmersson, 2020). Thus, innovation capabilities aim to compete with their competitors who are bigger and have more resources. Empirical evidence on innovation capability in the context of small businesses has been divided into two lines of research: one that studies the determinants of innovation capability, and one that studies the consequences of innovation capability. Thus, small business innovation has been considered either as a process or as an outcome. According to (Siahaan \& Tan, 2020) innovation capability can measure the extent to which a company has the potential to develop innovative capabilities and technology orientation enables a better increase in the company's innovation capability. The need for MSMEs to start the innovation process early can foster an innovative and open-minded organizational culture that is constantly developing new ideas and products. A faster pace of innovation will allow companies to meet the challenges that arise in a rapidly changing environment, will be able to change the market environment more proactively.

Previous studies have reviewed these two areas of the innovation capability literature. organizational innovation, incremental and radical innovation in product development decisions, innovation terminology and typologies of technological innovation, innovation management measures with the aim of establishing a framework that can be used to assess enterprise-level innovation activity, organizational innovation linking leadership, innovation as a process, and innovation as outcomes, certain types of innovation and open innovation. Despite the large number of innovation reviews, this article focuses more on innovation orientation and innovation capabilities in a small business context. The goal is to increase understanding of the characteristics of technology orientation and innovation capabilities in the context of small businesses in the era of digital transformation 4.0. This is done by means of a systematic review of empirical research.Previous research on innovation capability shows the relationship between innovation capability and intellectual capital (Yesil \& Dogan, 2019), and technology orientation (Salojärvi et al., 2015).

This article contributes to the literature by showing that in the era of the industrial revolution 4.0, a digital transformation process is needed where the condition of small companies requires a technology orientation and tends to pursue high innovation capabilities. This article also contributes to the literature by advancing current understanding of how technology orientation and innovation capability are related to performance outcomes at the enterprise level.

This article is structured as follows: the "Research approach" section presents the research approach used for this study. The "Findings" section presents the main results. Finally, conclusions and limitations in the "Conclusions" section.

\section{Systematic review of the technology orientation and innovation capability literature}

This article presents the results of a systematic review of the technology orientation and innovation capability literature in the context of small businesses. Included articles are limited to a few peer-reviewed articles with empirical evidence. This article provides coverage on current issues. The selection process for this study includes several steps, each step is to insert or remove articles according to predetermined criteria (Figure 1).

Choose potential with review plan and relevant $(\mathrm{n}=1000)$

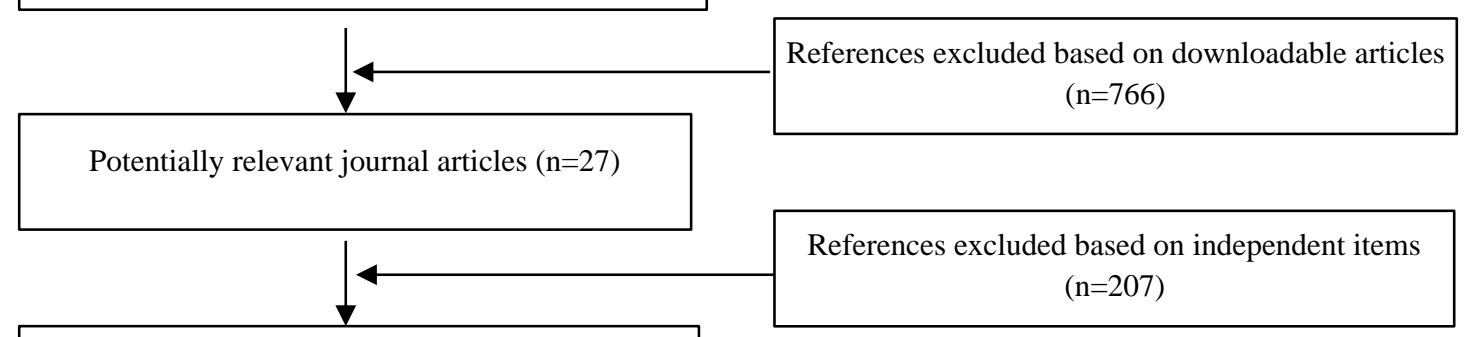

Potentially relevant journal articles with exact object categories and can be downloaded $(n=237)$ 
Figure 1: Literature selection process

The first stage includes the initial search. At this stage, the selection of articles is based on the search for relevant journal articles from the sciencedirect website database. The use of scientificdirection limits the number of articles analyzed, as the reviews are targeted at leading journals. The number of publications is significantly higher in other databases such as Google Scholar, but it also contains all types of publications including work papers, conference papers, and student assignments, that you want to exclude from searches. The search was conducted using the following keywords: "innovation capability*”, "orientation technology*”, "digital transformation*", , and "SMEs / MSMEs", search titles, abstracts and keywords. A total of 1000 related articles were found.

In the second stage, the article is removed if there is no article that can be downloaded. This phase limits the number of articles to 237 articles. In the third stage, articles are excluded if articles that do not meet the predetermined criteria are excluded. This phase reduces the number of articles to 13 .

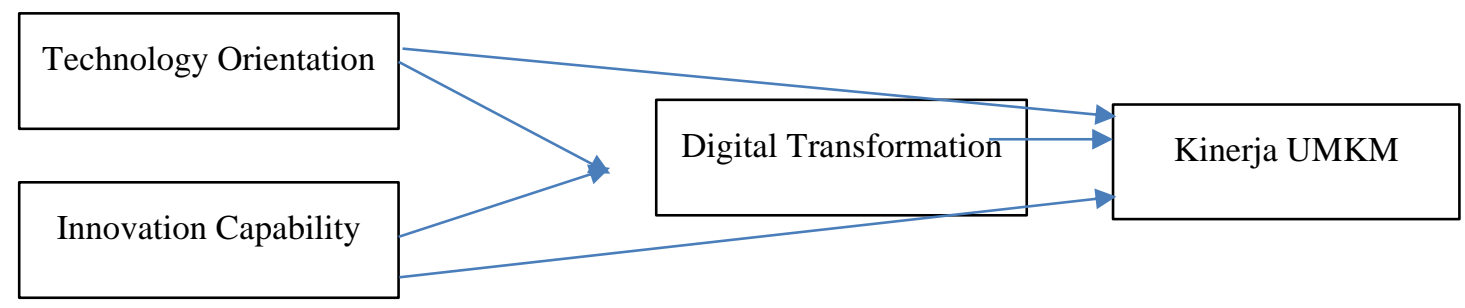

Figure 2: Research design.

\section{Classifications of innovation capabilities}

There are two classifications of innovation capabilities, innovation as a process and innovation as a result in the context of small businesses. In research that considers innovation as a process, a common way to conceptualize innovation capability is to think of it as the potential to create innovative outcomes (Dadfar et.al., 2013). In this study, innovation capability is considered as a onedimensional phenomenon including actions that can be applied to improve the performance of SMEs (Castela et. al., 2018). They conceptualize innovation capability as "the ability to continuously transform knowledge and ideas into new products, processes and systems for the benefit of the company and its stakeholders". (Zhang and Hartley, 2018) stated that innovation capability focuses on utilizing experiences and ideas from different origins. Improvement proficiency, similarly as those possibility with make inventive outputs characterizes Different measurements that together help helter skelter improvement proficience (Saunila, 2017). These incorporate for instance leadership, authoritative culture, usage from claiming outside knowledge, competency management.

A few investigations characterize different sorts about abilities that contain aggregate improvement proficiency (Oura et.al., 2016). These also include for example learning ability, entrepreneurial ability, marketing ability, networking ability, and resource exploitation ability. In the context of small business, there is also a single study that divides innovation capabilities into sensing, seizing, and transforming capabilities. (Fitz-Koch \& Nordqvist, 2017. Innovation capability as the capacity to produce different types of innovation, such as product innovation, process innovation, or organizational innovation. Product innovation is the most studied type of individual innovation (Landoni et. al., 2016), but process innovation is significantly under-studied (Hervas et. al., 2016). Product innovation capability and process innovation capability are also studied together (Mejía et.al., 2017).In addition, a large number of studies have considered all recognized types of innovation. in general, which means innovation in products, processes, organization, and marketing, together (Bruhn et.al., 2016; De Martino \& Magnotti, 2018; Ilori et.al, 2017; Maldonado et.al., 2018) .

Small companies put more emphasis on leadership that supports innovation capabilities (Saunila \& Ukko, 2014). In addition, (Bruhn et. al., 2016) found evidence of resource limitations small firms as export firms with more than 70 employees were more likely to adopt organizational and strategic innovations. The focus of most studies is on small businesses in general (Castela et.all., 2018; Hervas-Oliver et.al., 2016; Saunila, 2017). However, there are many studies that concentrate mainly on the manufacturing sector (Kafetzopoulos \& Psomas, 2015; Kim, Park, \& Paik, 2018; Zhang \& Hartley, 2018).

\section{Contribution: Innovation capability}

\section{Determinants of innovation ability}

Based on the review, the level of innovation ability is determined by several aspects. These determinants including top management leadership (Kim et.al., 2018), knowledge development (Saunila \& Ukko, 2014), and external networks (Kim et.al., 2018) suggest that intermediary organizations can advance available innovation resources. for small businesses, while (Siahaan \& Tan, 2020) innovation is an important determinant for superior company performance. In turn, organizational rigidity and insufficient resources 
can hinder innovation capability (Kim et.al., 2018). There is also research that considers the determinants of the commonly recognized types of innovation, meaning innovation in products, processes, and organizations. Technology intensity was also found to be associated with product innovation (Bruhn et al., 2016). Valaei et.al., 2016) found that product and process innovation ability was positively influenced by exploitative learning strategies. (Bruhn et.al., 2016) shows that organizational innovation is associated with external relations.

\section{Innovation capability and performance}

The majority of studies find a positive relationship between innovation ability and firm performance in the context of small businesses (eg, Oura et.al., 2016; Zhang \& Hartley, 2018). Based on the review, innovation capability is connected to new product performance (Zhang \& Hartley, 2018), brand performance (Odoom \& Mensah, 2018), and overall form performance (Dadfar et.al., 2013;). (Dadfar et. al., 2013) concluded that the prerequisites for this relationship are for example an effective organizational structure, learning, processes and relationships with suppliers, customers, and other networks. In addition, the individual determinants of innovation capability proved to be effective in company performance. (Oura et.all., 2016) found that innovation capacity (consisting of several interrelated capabilities) has an impact on export performance which is shaped by financial, strategic, and satisfaction-related aspects. The results from Saunila (2017) show that three dimensions of innovation ability, referred to as participatory leadership culture, knowledge development, and idea structure and organization, are connected with firm performance. Different types of innovation also contribute to the company's performance. Product innovation capability is related to growth performance (O'Cass \& Sok, 2014), and overall competitive advantage (Landoni et.all., 2016). However (O'Cass and Sok, 2014) states that product innovation capabilities must be accompanied by high intellectual resources. The results from (Landoni et.all., 2016) apply to specific design innovation capabilities which they perceive to be effective even in the short term. Furthermore, different types of innovation capabilities, meaning innovation in products, processes, organization, and marketing, contribute to operational performance (Kafetzopoulos \& Psomas, 2015), and business returns (Maldonado et. al., 2018). The results of (Kafetzopoulos and Psomas, 2015) do not reveal a direct effect of this type of innovation capability on financial performance, but the relationship is facilitated by operational performance. In contrast to other studies, (Mejía Vallejo and Arias-Pérez, 2017) found that product and process innovation capabilities do not guarantee sales growth or market share.

\section{Digital Transformation}

Digital transformation is a very important process of change in the era of the industrial revolution 4.0. Changes in all occupations and are part of the income generation strategy, and the application of a flexible or agile management model in the face of competition. It takes a fast process to meet rapidly changing demands, a process of reinventing more sophisticated businesses following digital technology to digitize operations and formulate extended supply chain relationships. Changes that require functional internet technology tools in design, manufacturing, marketing, sales, presentation and are data-based management models. Making changes requires collaboration for innovation from the best team work to produce the best product quality and service quality.

\section{Conclusion}

This systematic review has highlighted four main themes of innovation capability in the small business context. First, empirical evidence suggests that innovation capability, conceptualized as a process or as an outcome, influences firm performance. Second, in a small business context, innovation capability is most often conceptualized as an outcome. Third, survey designs dominate the field, whereas few studies have adopted qualitative designs. Fourth, innovation capabilities are often studied in small businesses in general or in the manufacturing sector.

Thus, this study contributes to research on the determinants of innovation ability (Kim et.al., 2018; Saunila \& Ukko, 2014), and the consequences on innovation ability (Oura et.al. 2016; Zhang \& Hartley, 2018). Considering the findings of this study, it is evident that conscious organizational actions related to the development of innovative outputs provide the basis for companies to maintain competitive advantage. Furthermore, two conceptualizations of innovation capability, innovation as a process and innovation as a result, are also well established in the context of small businesses.

For practitioners, these findings reveal that small businesses can take advantage of various forms of innovation capabilities. Some companies rely on their ability to generate product innovation, while others define several actions that together contribute to innovation capabilities. Furthermore, the company's performance can be influenced by taking into account the ability of innovation. However, there is no general acceptance for the successful utilization of innovation capabilities. Instead, managers must find the right dimensions of innovation capabilities based on their particular business needs. The main limitation of this research is the difference in different ways and points of view.. The initial search was carried out through the direct science website database. Keywords were chosen to cover the phenomenon as much as possible, but there is still the possibility of missing relevant articles. In addition, the inclusion and exclusion criteria were made as clear as possible but there is a possibility that relevant articles were missed because decisions were made with the personal judgment of the researcher.

Author Contributions: Conceptualization, R.E., C.A. and Z.P.; methodology, Z.P. and R.E.; validation, Z.P., R.E. and S.T.; formal analysis, Z.P. and R.E.; investigation, R.E. and S.T.; resources, R.E. S.T. and C.A.; writing—original draft preparation, Z.P. and R.E.; writing—review and editing, Z.P., R.E. and C.A. All authors have read and agreed to the published version of the manuscript. 
Institutional Review Board Statement: Ethical review and approval were waived for this study, due to that the research does not deal with vulnerable groups or sensitive issues.

Data Availability Statement: The data presented in this study are available on request from the corresponding author. The data are not publicly available due to privacy.

Conflicts of Interest: The authors declare no conflict of interest.

\section{References}

Al-Kalouti,J., Kumar, V., Kumar, N., Garza-Reyes, J. A., Upadhyay, A., \& Zweigelaar, J. B. (2020). Investigating innovation capability and firm performance in service firm. Strategic Change, 29(1), 103-113.

Bruhn, N. C. P., Alcântara, J. N., \& Calegário, C. L. L. (2016). Multinationalenterprises and spillover effects: A study on the factors associated with theinnovation capacity of SMEs in Brazil. Espacios, 37(10), 59-73

Castela, B. M., Ferreira, F. A., Ferreira, J. J., \& Marques, C. S. (2018). Assessing theinnovation capability of small and medium sized enterprises using a non-parametric and integrative approach. Management Decision, 56(6), 1365-1383.

Dadfar, H., Dahlgaard, J. J., Brege, S., \& Alamirhoor, A. (2013). Linkage betweenorganisational innovation capability, product platform development andperformance: The case of pharmaceutical small and medium enterprises iran. Total Quality Management \& Business Excellence, 24(8), 819-834.

De Martino, M., \& Magnotti, F. (2018). The innovation capacity of small food firmsin Italy. European Journal of Innovation Management, 21(3), 362-383.

Fitz-Koch, S., \& Nordqvist, M. (2017). The reciprocal relationship of innovationcapabilities and socioemotional wealth in a family firm. Journal of Small Business Management, 55(4), 547-570.

Hacioglu, U., \& Sevgilioglu, G. (2019). The evolving role of automated systems and its cyber-security issue for global business operations in Industry 4.0. International Journal of Business Ecosystem \& Strategy (2687-2293), 1(1), 01-11. https://doi.org/10.36096/ijbes.v1i1.105

Hacioglu, U. (2020). Digital business strategies in blockchain ecosystems. Springer International Publishing, https://doi.org/10.1007/978-3-030-29739-8.

Hervas-Oliver, J. L., Boronat-Moll, C., \& Sempere-Ripoll, F. (2016). On processinnovation capabilities in SMEs: A taxonomy of process-oriented innovativeSMEs. Journal of Small Business Management, 5(4), 113-134.

Hilmersson Firouze Pourmand A, Hilmersson Mikael, (2020), Networking to accelerate the pace of SME innovations, Journal of Innovation \& Knowledge, 6 (1), 43-49, doi.org/10.1016/j.jik.2020.10.001

Hogan, S. J., Soutar, G. N., McColl-Kennedy, J. R., \& Sweeney, J. C., (2011), "Reconceptualizing professional service firm innovation capability: Scale development", Industrial Marketing Management, 40 (8), 1264-1273.

Ilori, A. B., Lawal, A., \& Simeon-Oke, O. O. (2017). Innovations and innovationcapability in palm kernel processing industry in southwestern Nigeria. International Journal of Innovation Science, 9(1), 102-114.

Kafetzopoulos, D., \& Psomas, E. (2015). The impact of innovation capability on theperformance of manufacturing companies: The Greek case. Journal of Manufacturing Technology Management, 26(1), 104-130.

Kim, M. K., Park, J. H., \& Paik, J. H. (2018). Factors influencing innovation capabilityof small and medium-sized enterprises in Korean manufacturing sector:Facilitators, barriers and moderators. International Journal of Technology Management, 76(34), 214-235.

Landoni, P., Dell'Era, C., Ferraloro, G., Peradotto, M., Karlsson, H., \& Verganti, R. (2016). Design contribution to the competitive performance of SMEs: The roleof design innovation capabilities. Creativity and Innovation Management, 25(4), 484-499.

Liu, Y., Diwei L. V., Ying Y., Felix, A., \& Jiang, W., (2018), "Improvisation for innovation: The contingent role of resource and structural factors in explaining innovation capability", Technovation, 74 (5), 32-41.

Maldonado-Guzmán, G., Garza-Reyes, J. A., Pinzón-Castro, S. Y., \& Kumar, V.(2018). Innovation capabilities and performance: Are they truly linked inSMEs? International Journal of Innovation Science, 2(1), 29-31

Martínez-Román, J. A., Tamayo, J. A., \& Gamero, J., (2017). Innovativeness and its influence on growth and market extension in construction firms in the Andalusian region, Journal of Engineering and Technology Management, vol. 43, pp. 19-33.

Mejía Vallejo, A., \& Arias-Pérez, J. (2017). Approach to differences in product and process innovation capabilities and financial performance in manufacturing companies. Espacios, 38(4), 49-61.

O'Cass, A., \& Sok, P. (2014). The role of intellectual resources, product innovationcapability, reputational resources and marketing capability combinations infirm growth. International Small Business Journal, 32(8), 996-1018.

Odoom, R., \& Mensah, P. (2018). Brand orientation and brand performance inSMEs: The moderating effects of social media and innovation capabilities. Management Research Review 4(3), 89-101.

Oura, M. M., Zilber, S. N., \& Lopes, E. L. (2016). Innovation capacity, internationalexperience and export performance of SMEs in Brazil. International Business Review, 25(4), 921-932.

Salojärvi, H., Ritala, P., Sainio, L. M., \& Saarenketo, S., (2015). Synergistic effect of technology and customer relationship orientations: Consequences for market performance. Journal of Business \& Industrial Marketing, 30 (5), 511-520.

Saunila, M. (2017). Innovation capability in achieving higher performance:Perspectives of management and employees. Technology Analysis \& Strategic Management, 29(8), 903-916. 
Saunila, M., \& Ukko, J. (2014). Intangible aspects of innovation capability in SMEs:Impacts of size and industry. Journal of Engineering and Technology Management, 33(1), 32-46.

Siahaan Dian Tauriana, Tan Caroline Swee Lin, (2020), Antecedents of Innovation Capability and Firm Performance of Indonesian ICT SMEs, Asian Journal of Business Research, 21(2), 73-85. DOI:10.14707/ajbr.20003

Valaei, N., Rezaei, S., \& Emami, M. (2016). Impact of exploitative learning strategyon Malaysian SMEs' creativity and innovation capabilities. International Journal of Management and Enterprise Development, 15(4), 328-354.

Yesil, S., \& Dogan, I. F., (2019). Exploring the relationship between social capital, innovation capability, and innovation., Innovation, vol. 21 , no. $4,506-532$.

Zhang, M., \& Hartley, J. L. (2018). Guanxi, IT systems, and innovation capability:The moderating role of proactiveness. Journal of Business Research, 90 (2), 75-86.

Publisher's Note: SSBFNET stays neutral with regard to jurisdictional claims in published maps and institutional affiliations.

\section{(c) (1)}

(C) 2021 by the authors. Licensee SSBFNET, Istanbul, Turkey. This article is an open access article distributed under the terms and conditions of the Creative Commons Attribution (CC BY) license (http://creativecommons.org/licenses/by/4.0/).

International Journal of Research in Business and Social Science (2147-4478) by SSBFNET is licensed under a Creative Commons Attribution 4.0 International License. 